\title{
A cidade caracterizada por seus espaços livres
}

\author{
Nayara Cristina Rosa Amorim, Glauco de Paula Cocozza*
}

Resumo O presente trabalho apresenta um estudo sobre a forma urbana, a paisagem e os espaços livres de Patos de Minas, cidade média de Minas Gerais - Brasil, buscando compreender a configuração do Sistema de Espaços Livres. O estudo segue por meio de análises sobre o suporte ambiental, a configuração espacial e inserção dos espaços livres na forma urbana, auxiliando a compreensão da relação sistêmica desses espaços, suas funções, potencialidades, apropriações e demandas de gestão, contribuindo assim para a leitura da estrutura morfológica da cidade.

Palavras-chave: sistema de espaços livres, paisagem urbana, forma urbana.

\section{The city characterized by its open spa- ces}

\begin{abstract}
This paper presents a study about the urban form, the landscape and the open spaces of Patos de Minas, average size city of Minas Gerais - Brazil, trying to understand the configuration of the Open Spaces System. The study proceed through analysis of the environmental support, the spatial configuration and integration of open spaces in the urban form, assisting in the understanding of the systemic relation between these spaces, functions, potentialities, appropriations and demand management, thus contributing to the reading of the morphological structure of the city.
\end{abstract}

Keywords: open spaces system, urban landscape, urban form.

\section{La ciudad caracterizada por sus espacios libres}

Resumen El presente trabajo presenta un estudio sobre la forma urbana, una perspectiva de los espacios libres de Patos de Minas, la ciudad media de Minas Gerais-Brasil, buscando una configuración del Sistema de Espacios Libres. A continuación se presenta un análisis sobre el soporte ambiental, una configuración espacial y una inserción de los espacios libres en la forma urbana, una descripción de la estructura sistémica de los espacios, sus funciones, las potencialidades, las adecuaciones y las demandas de la gestión, contribuyendo así a una lectura de la estructura morfológica de la ciudad.

Palabras clave: sistema de espacios libres, passaje urbana, forma urbana. 
trabalho apresentado é parte dos resultados e indagações de uma dissertação de mestrado desenvolvida no Programa de Pós-Graduação em Arquitetura e Urbanismo - PPGAU - da Faculdade de Arquitetura Urbanismo e Design - FAUeD, da Universidade Federal de Uberlândia em 2015, com fomento da FAPEMIG.

A pesquisa investiga os aspectos formais dos espaços livres, características espaciais, distribuição na malha urbana, os aspectos funcionais; o entendimento das especificidades legais, políticas, sociais e ambientais inerentes no processo de urbanização e formação, auxiliando na compreensão da estrutura morfológica da cidade de Patos de Minas. Observando as principais características desses espaços livres, sua relevância para a paisagem urbana e identidade da cidade, bem como suas articulações com a malha urbana e com a população local, ressaltando suas potencialidades, funções e fragilidades. A pesquisa gera um material técnico-científico que pode contribuir para a gestão desses espaços, para o planejamento urbano e ambiental de Patos de Minas, contribuindo para formação de uma cidade mais sustentável.

O espaço livre de edificação é parte estruturante da forma urbana e se configura em diferentes categorias, tipologias e características no meio urbano, principalmente pela introdução ao longo da história de diferentes padrões urbanísticos nas cidades. O processo de urbanização das cidades é uma soma e por vezes até uma sobreposição de padrões morfológicos, esses traçados geram diferentes paisagens com diferentes tipos de espaços livres, incorporando ao sistema um rico mosaico espacial, formado por diferentes porcentagens de espaços livres incorporados aos lotes característicos de traçados diferentes, por distintos tipos de praças, áreas de preservação, parques, ruas e avenidas. Áreas essas que apresentam diversos conflitos e possuem um intenso potencial de transformação.

Segundo Macedo, et al. (2012), as cidades brasileiras possuem padrões morfológicos semelhantes, isso fica evidente na repetição dos tipos de traçado (ortogonais, irregulares, orgânicos, radiais, etc.) e nos padrões de mancha urbana (linear, tentacular, compacta, mista, etc.). O que confere a especificidade das diversas cidades é a forma como elas estão inseridas em seu contexto territorial, os arranjos espaciais, seus padrões culturais, socioeconômicos, a legislação municipal, as tipologias e funções dos espaços livres e a paisagem urbana.

* Nayara Cristina Rosa Amorim é Arquiteta e Urbanista, professora da Faculdade de Arquitetura da Universidade Federal da Bahia, ORCID <https://orcid.org/00000002-6653-457X>; Glauco de Paula Cocozza é Arquiteto e Urbanista, professor da Faculdade de Arquitetura Urbanismo e Design da Universidade Federal de Uberlândia, ORCID <https://orcid. org/0000-0001-5275-1357>.
Nas cidades médias as formas como os padrões morfológicos se adequam ao suporte físico, transformando paisagem local, conferem ao SEL diferentes dinâmicas espaciais, funcionais e tipológicas.

\section{Mapeamento da área de estudo: Patos de Minas}

Patos de Minas, objeto de estudo desse trabalho, é uma cidade média da região intermediária à Mesorregião do Triângulo Mineiro e Alto Paranaíba. Segundo o 
IBGE (2016), a região possuía uma população estimada de 148.762 habitantes em 2015, uma unidade territorial de 3.189,771 $\mathrm{km}^{2}$ e densidade demográfica de 43,49 $\mathrm{hab} / \mathrm{km}^{2}$. A forma urbana patense teve seus primeiros traços no final do século XIX, às margens de uma lagoa de patos silvestres, em uma planície composta por cerrado, entre o Rio Paranaíba e os Córregos do Monjolo e da Cadeia, uma terra com boa disponibilidade de recursos hídricos, propícia a agricultura.

Para auxiliar o processo de entendimento da forma, da paisagem urbana e a configuração do Sistema de Espaços Livres de Patos de Minas, foram feitas análises e mapeamentos caracterizando o suporte ambiental, a configuração espacial da malha urbana e a inserção dos espaços livres no tecido. Esses levantamentos foram feitos com base na Planta Geral de Patos de Minas (referente a 2015) fornecida pela Prefeitura Municipal, cujos dados foram verificados e atualizados a partir de imagens de satélite Google(2015) e visitas aos locais.

A metodologia de identificação do Sistema de Espaços Livres vem sendo desenvolvida pelos estudos da rede nacional brasileira QUAPÁ-SEL (Quadro do Paisagismo Brasileiro - Sistema de Espaços Livres) coordenada pelo LAB-QUAPÁ da Faculdade de Arquitetura e Urbanismo da Universidade de São Paulo (SCHELEE et al., 2009; CAMPOS et al. 2012).

Ao aplicar a metodologia, se constatou que boa parte dos exemplos de aplicação era em cidades de grande porte, e poucas aplicações em cidades de médio porte onde os espaços livres desempenham funções diferentes. Busca-se entender o contexto ambiental, morfológico e cultural de uma cidade que ainda estabelece muitas relações de subsistência e lazer com a área rural. Uma cidade que abriga a dualidade de engarrafamentos na porção central e criação de gado nos bairros periféricos.

\section{Espaços Livres e relações ecológicas}

Com relação ao suporte ambiental, Patos de Minas está localizada entre o Rio Paranaíba e os fundos de vale que abrigam as nascentes de alguns córregos que correm em direção ao rio. O Rio Paranaíba é um elemento do suporte físico da paisagem local, limite da forma urbana em sua porção oeste. Os córregos e fundos de vale formam reentrâncias não loteadas na forma da cidade, a região possui também lagoas que se inserem na paisagem da cidade de diferentes modos, ora conectados à malha urbana formando espaços de lazer e contemplação, ora desconectados da malha urbana e associados à esfera rural. A Figura 1 a seguir apresenta o levantamento dos principais espaços que desempenham funções ecológicas na forma urbana.

Com base na Figura 1 pode-se perceber que as áreas ocupadas por fundos de vale contribuem para delimitação da mancha urbana, são possíveis vetores de expansão da cidade, esses locais abrigam as nascentes dos cursos d'água que permeiam a malha urbana, esses vales desempenham funções ambientais e abrigam atividades agropecuárias, além de caracterizarem a paisagem da cidade. Pode-se constatar que, em Patos de Minas, grande parte dos córregos incorporados à malha está canalizada e tiveram suas áreas de proteção permanente (APP) desmatadas, são zonas de topografia acidentada, propícias a enchentes e com baixo índice de arborização. 


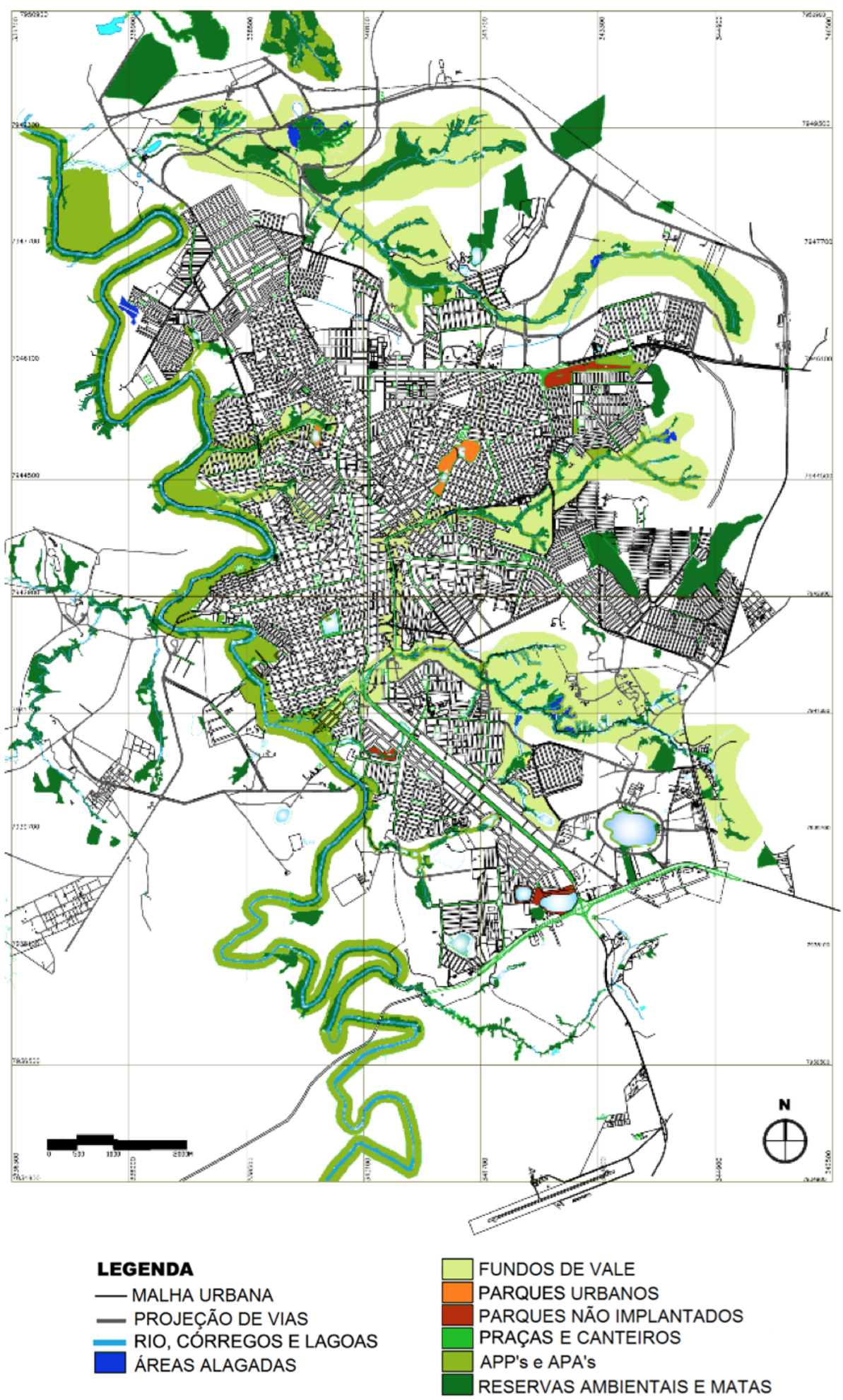

Figura 1: Relação Ecológica. Fonte: Elaborado pelos autores. Baseado em Mapas da Prefeitura Municipal de Patos de Minas, 2015. 
A Lagoa dos Patos, que deu nome à cidade (localizada no Centro) foi aterrada, inicialmente transformada em no campo de futebol do Esporte Clube Mamoré, o campo funcionava como uma bacia de detenção de água no período chuva, permitindo a infiltração. Em 2007 o campo de futebol deu lugar a um shopping e supermercado, os estudos de impacto ambiental e de vizinhança foram aprovados pela Prefeitura Municipal e órgãos ambientais. Essa impermeabilização contribui para alagamentos mesmo após obras de ampliação da capacidade do sistema de drenagem pluvial na área. Não foi feito nenhum plano de compensação com mais áreas permeáveis na bacia hidrográfica, principalmente por se tratar do centro da cidade, uma área consolidada e adensada.

Observa-se que esse processo de aterramento das lagoas permanece, desconsiderando as funções ambientais desses espaços livres. O crescimento urbano está se aproximando das áreas de outras lagoas e nascentes de córregos, impermeabilizando as áreas de recarga das mesmas, contribuindo para diminuição gradativa da lamina d'água, processo ambiental analisado em outros contextos por Spirn (1984); Gorski (2010). Outro problema é a poluição desses corpos d'água que estão inseridos no tecido urbano, onde as águas pluviais são jogadas sem tratamento da poluição difusa e com esgotos clandestinos. De acordo com Bonzi (2015) e Pinheiro (2017), a poluição difusa é carregada com as primeiras chuvas para o sistema hídrico, o que pode causar danos substanciais à qualidade das águas, parte dessa carga poderia ser filtrada/retida com a recuperação da mata ciliar. De acordo com Tucci(2005) e AESABESP (2008), atualmente, a poluição difusa é considerada como a maior fonte de poluição dos corpos hídricos urbanos, ela é formada por resíduos de origem bastante diversificada, como os provocados pelo lixo acumulado nas ruas, desgaste do asfalto pelos veículos, as decomposições orgânicas, as sobras de materiais das atividades de construção, os restos de combustíveis, óleos e graxas deixados por veículos, poluentes do ar, etc.

Considerando a necessidade de entender o funcionamento dos espaços livres de maneira sistêmica, para garantia de que as funções e relações desempenhadas pelos mesmos sejam mantidas, observa-se que as lagoas em Patos de Minas desempenham função central nesse sistema, tanto pelas funções ambientais desempenhadas como por conferir identidade à cidade. Elas também são importantes pela função de lazer que podem desempenhar, entretanto essa função poderia ser potencializada, aumentando a área permeável em torno desses corpos d'água. A figura a seguir representa a distribuição dos espaços livres no entorno de uma das lagoas.

Segundo a Lei de Uso e Ocupação do Solo de Patos de Minas (2008), as áreas verdes são porções situadas na Macrozona Urbana destinadas a oferecer espaços públicos adequados e qualificados às atividades de recreação, lazer e turismo da população, de forma a conciliar a proteção dos bens naturais e culturais. Entretanto foi observado o isolamento das Áreas de Preservação Permanentes (APP's) e das Áreas de Reserva Legal (ARL) em grande parte da cidade, por meio de cercas e restrições de acesso geram enclaves no tecido urbano e dificultam a interação entre os moradores e a paisagem, como também ocorre nas áreas ambientais de outras cidades conforme Souza e Macedo (2014), Queiroga (2011). Esse tipo de tratamento faz com esses espaços livres sejam vistos pela população como áreas mal iluminadas propícias à 


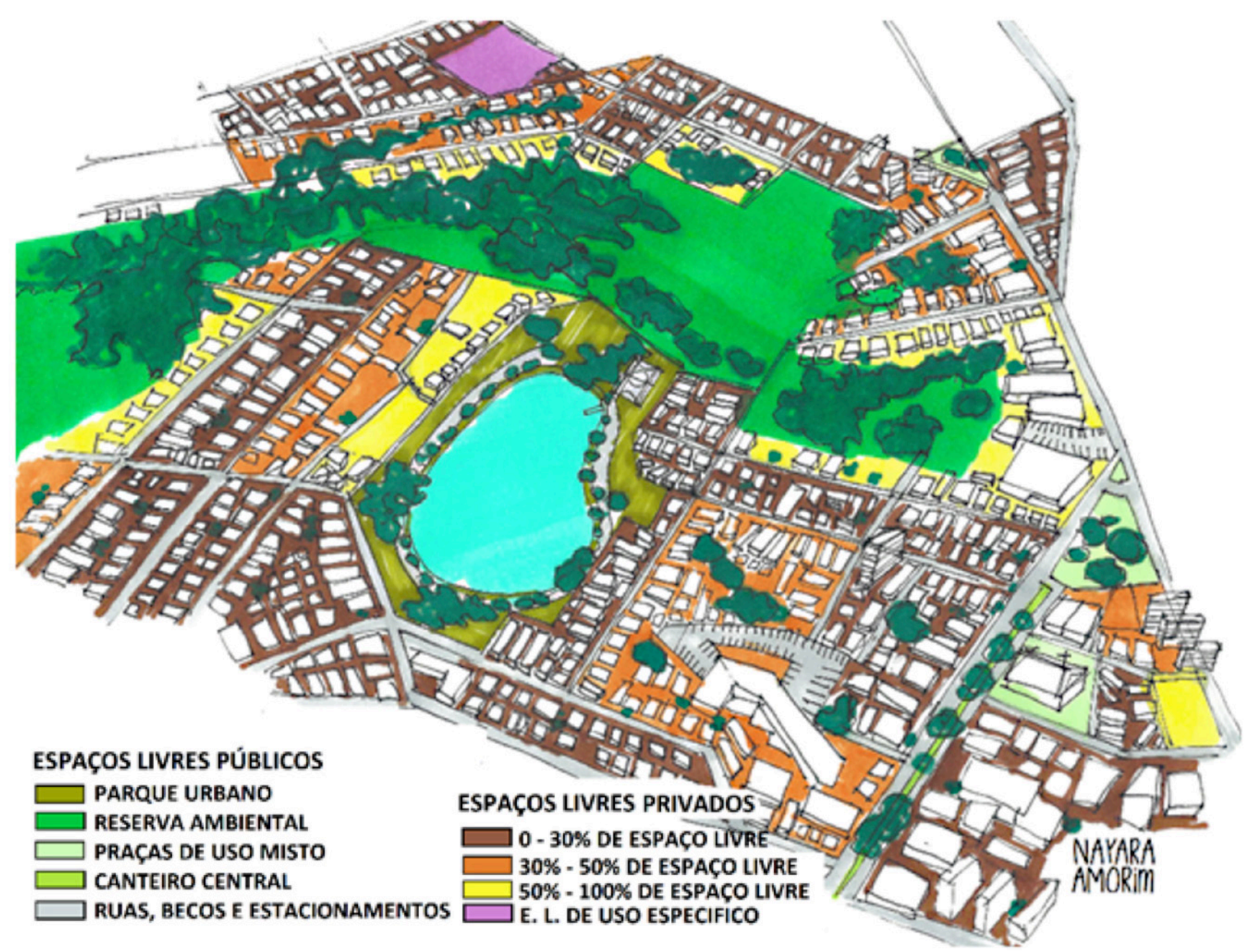

Figura 2: Distribuição dos espaços livres públicos e privados no entorno do Parque Lagoinha em Patos de Minas. Fonte: AMORIM, 2015. violência, atividades ilícitas e à concentração de animais peçonhentos. Gerando, assim, ações por parte dos moradores como: queimadas clandestinas (como ocorreu na Mata do Catingueiro e na Mata do Tonheco no Parque do Mocambo) e depósito de lixo. O desafio é integrar às APP's e ARL's a dinâmica urbana, promovendo a interação dos moradores com essas áreas.

O estudo das relações ambientais e dos atributos físicos da paisagem é importante para orientar as ações de planejamento da cidade. Segundo autoras como Tardin (2010) e Ribeiro (2010) uma ocupação urbana mais adequada exige um planejamento eficiente da paisagem, que reconheça sua estrutura morfológica, identificando as saliências e reentrâncias, encostas, fundos de vale, topos, talvegues, linhas de drenagem, afloramentos rochosos, vegetação nativa, matas e reservas biológicas, cujas características ambientais devem ser condizentes aos projetos para esses espaços. 
Figura 3: Configuração urbana e Usos predominantes do solo. Fonte: Elaborado pelos autores. Baseado em Mapas da Prefeitura Municipal de Patos de Minas, 2015.

\section{A configuração da malha urbana}

Partimos para análise da configuração da malha urbana apresentada na Figura 3 espacializando o processo de consolidação do tecido urbano, evidenciando: o núcleo que deu início ao povoado, a malha urbana consolidada, a malha em processo de consolidação e os vetores de crescimento da cidade, buscando compreender como os espaços livres estão inseridos nessas áreas. A pesquisa também apresenta a distribuição dos loteamentos fechados e das áreas de Habitação de Interesse Social (HIS), entendendo os mesmos como padrões morfológicos.

Ressaltando aspectos da configuração urbana a Figura 3 evidencia a existência de um padrão na distribuição e predominância do uso do solo, entre uso: residencial, comercial, industrial, de serviços e misto. Analisando a Figura 3 podemos perceber que a porção territorial central que corresponde ao início da urbanização é uma área de uso misto (residencial/comercial/serviços), corresponde à área mais verticalizada e a que mais concentra fluxos de pessoas e mercadorias. Nessa área temos a concentração de praças de pequeno porte.

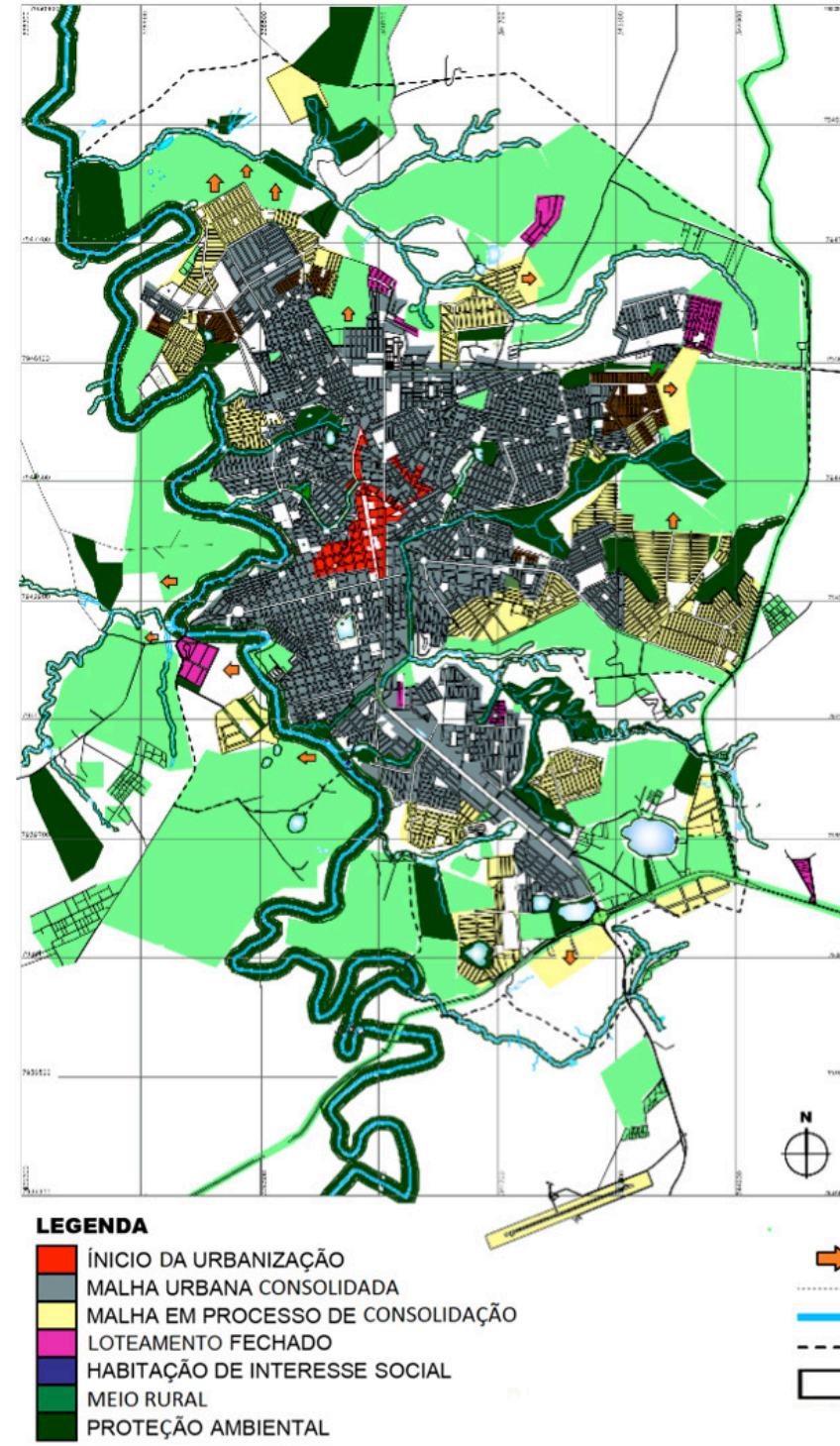

risco.

MEIO RURAL

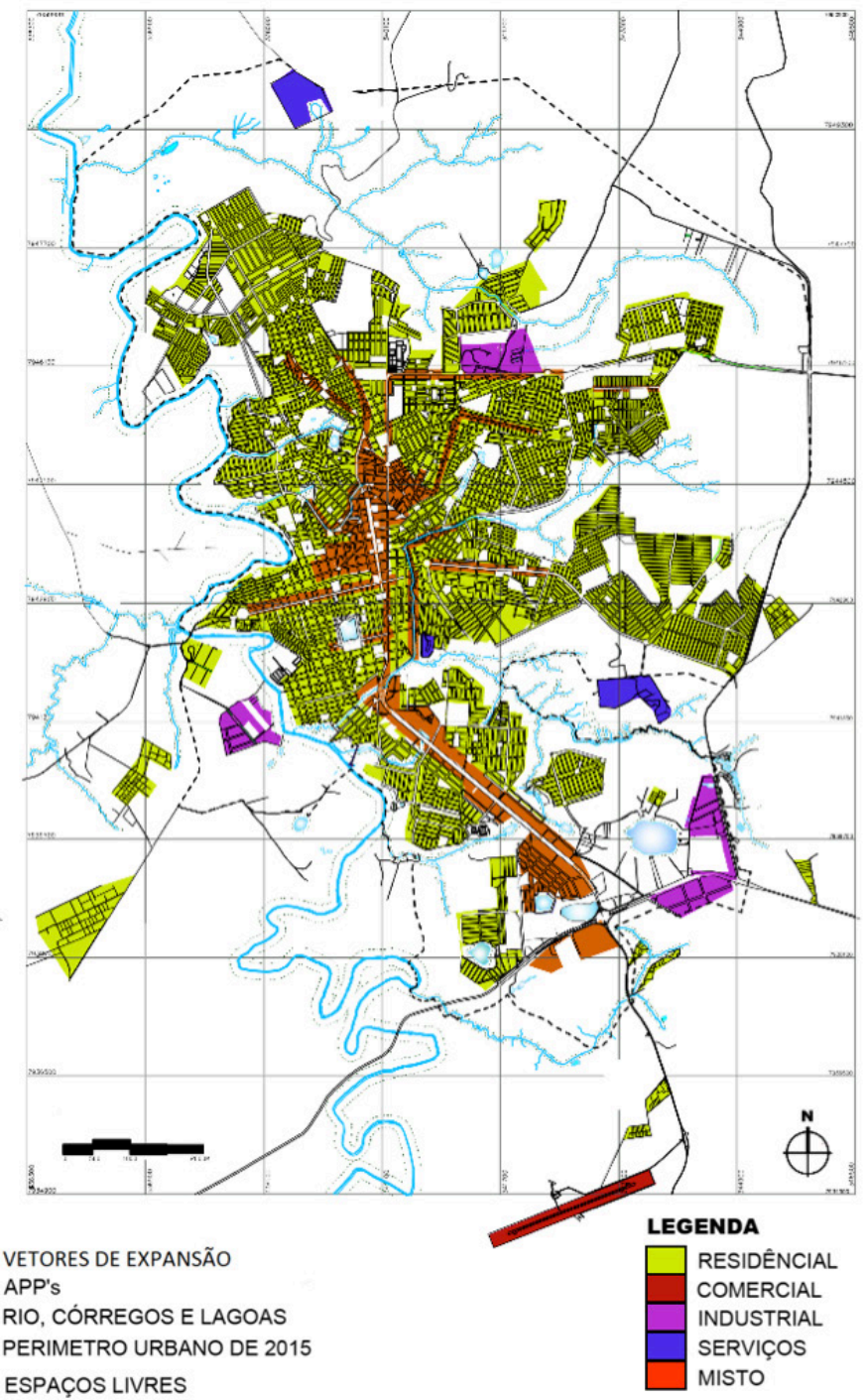

MISTO 

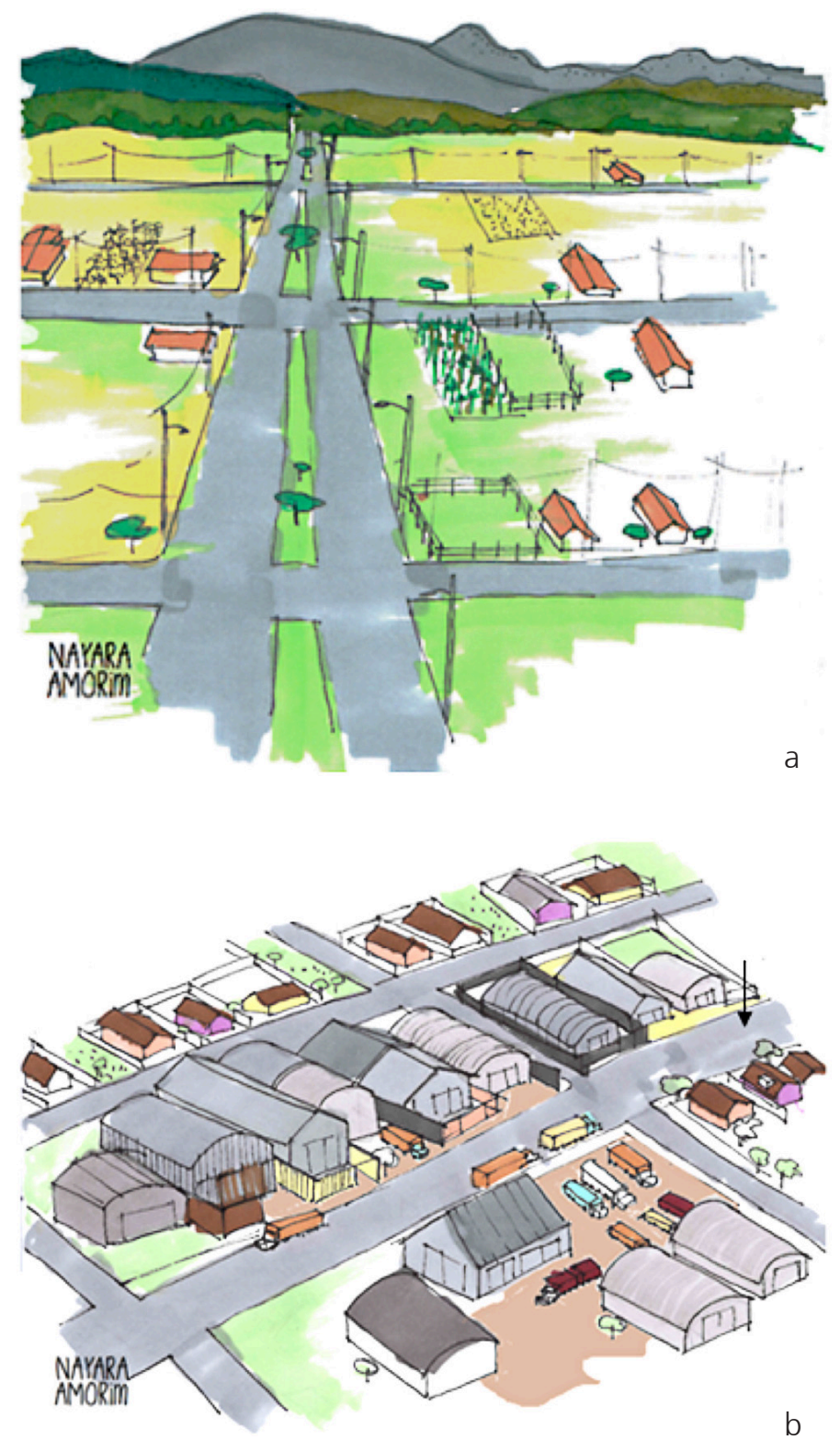

Figura 4: Malha urbana em processo de consolidação no Bairro Residencial Barreiro (a) e Bairro Planalto na Zona Sul (b) de Patos de Minas. Fonte: AMORIM, 2015.
Grande parte da malha urbana em processo de consolidação é considerada de uso predominante residencial (Figura 4a), e não possuem sub-centros ou eixos comerciais ou de uso misto. Nessa área temos uma concentração de espaços públicos destinados a praças segundo a Planta Cadastral da Prefeitura. Mesmo sem apresentar um adensamento consolidado, essa área possui uma baixa arborização devido às características de árvores espaçadas do bioma cerrado. Atualmente a prefeitura tem exigido para aprovação dos loteamentos um plano de arborização, porém não é exigido o plantio das espécies nativas

Observa-se que a zona sul da cidade possui um eixo central de uso misto (residencial/ comercial/industrial), formado por galpões, funilarias e residências, o que confere uma variação de gabaritos na paisagem (Figura 4b). 
Figura 5: Tipologias de traçado urbano e espaços livres e traçado urbano. Fonte: Elaborado pelos autores, baseado em mapas da Prefeitura Municipal de Patos de Minas, 2015.
Outro aspecto da configuração espacial patense, importante de ser analisada, são os tecidos urbanos, padrões morfológicos que vistos em conjunto caracterizam a malha urbana e a organização espacial dos espaços livres. Os traçados se distinguem em geral por sua predominância geométrica, por sua continuidade física, padrão de desenho viário, predominância de tamanho de quadra e lote, assim como pelo suporte físico em que estão inseridos: topografia, tipo de solo, presença hídrica, arborização, paisagem, dentre outros. Os tipos de traçados presentes na forma urbana estão apresentados na Figura 5.

Uma das suspeitas ao realizar o mapeamento das tipologias de traçado e da forma de inserção dos espaços livres na malha é que existia uma relação direta entre os dois. Entretanto, como se pode constatar pela Figura 5, a distribuição e conformação das áreas não edificadas públicas não se restringe aos condicionantes dos tipos de traçado.

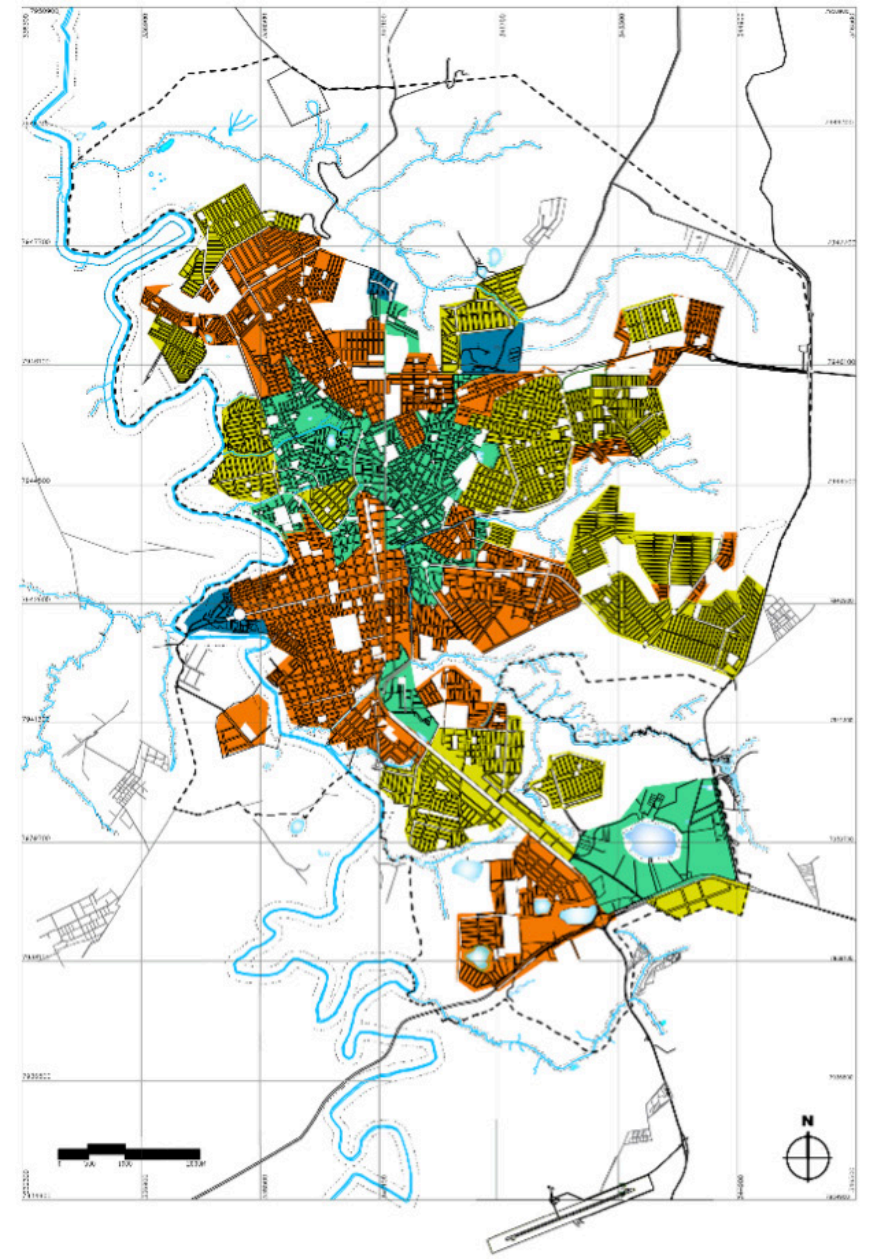

LEGENDA

TRAÇADO IRREGULAR TRACCADO ORTOGONAL IRREGULAR TRACCADO ORTOGONAL REGULAR TRAÇADO ORGÂNICO TRAÇADO MISTO ESPAÇOS LIVRES

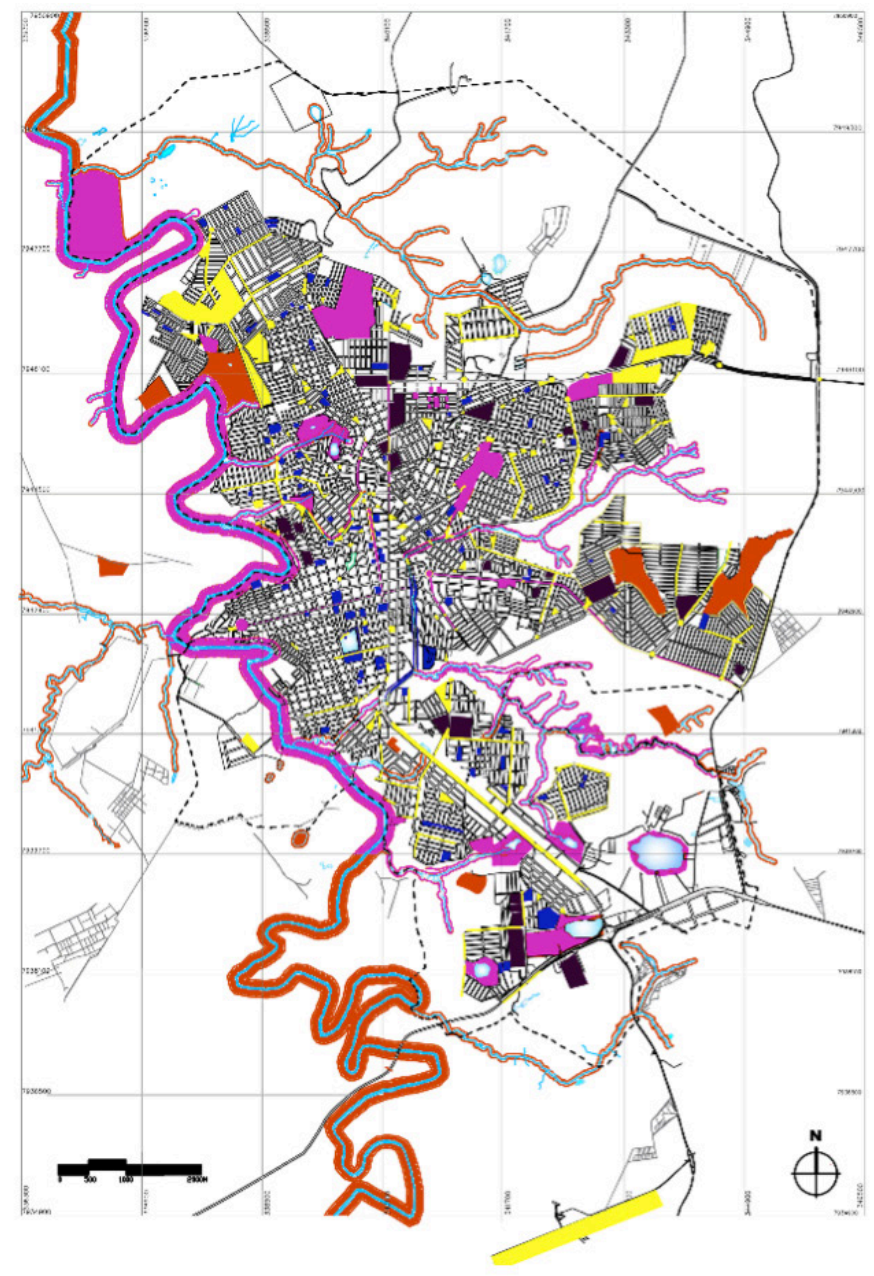

LEGENDA

E. L. INDEPENDENTE DO TRAÇADO

E. L. ALTERAVGERA O TRACCADO

E.L. INSERIDO NO TRACCADO

E.L DE UNIÕES DO TRAÇADO

E. L DE SOBRAS DO TRAÇADO 


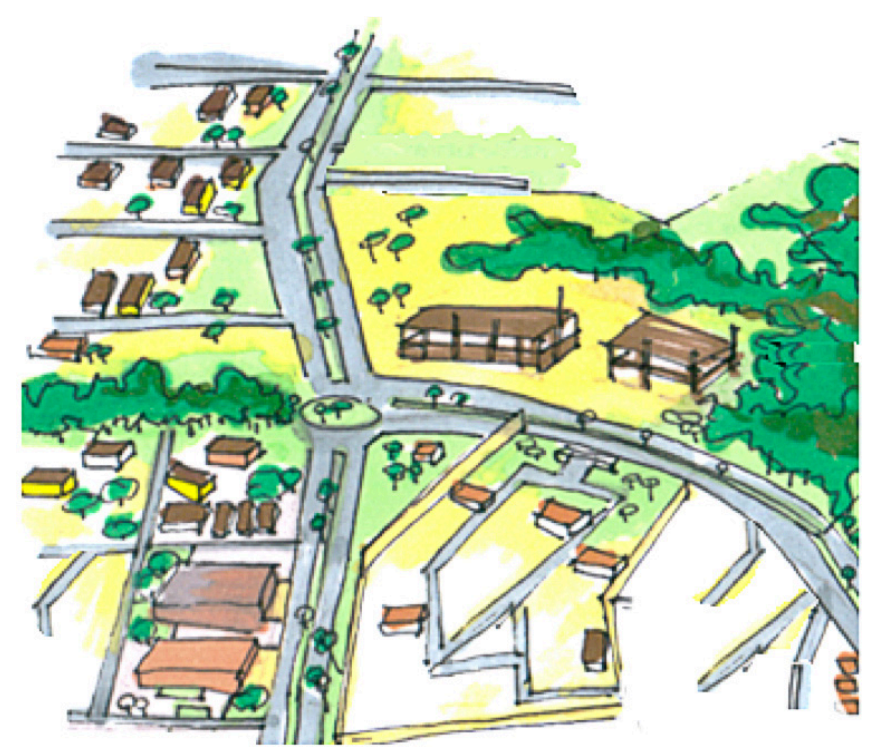

a

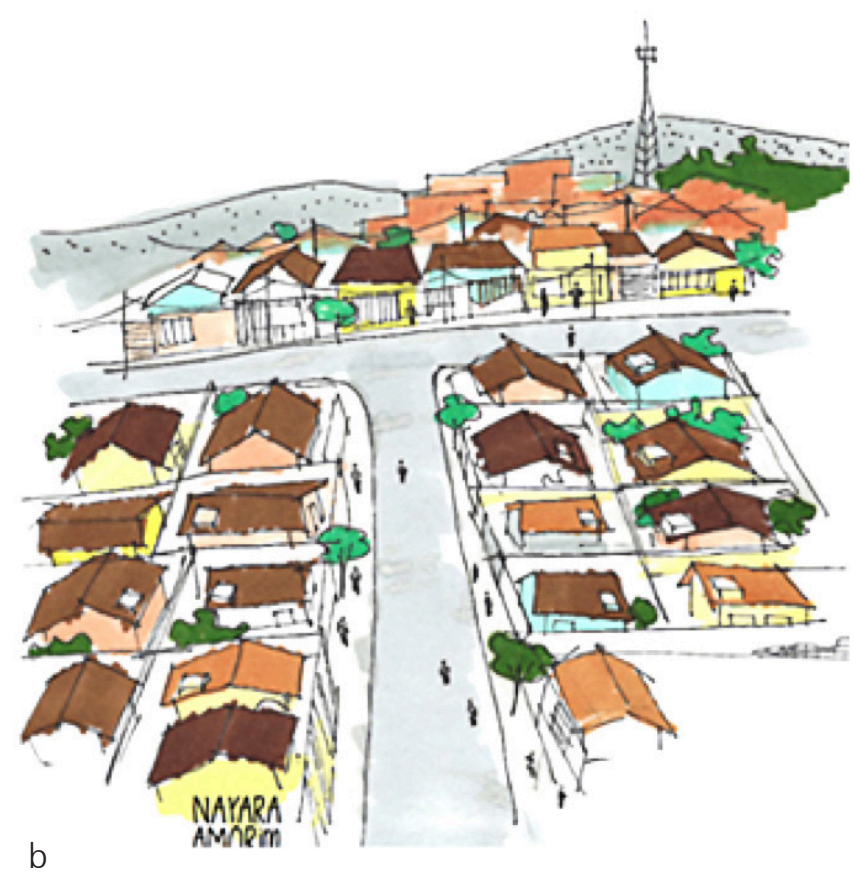

Figura 6: Encontro do Córrego da Cadeia com Av. Padre Almir (a), e homogeneização da porcentagem de espaços livres dentro dos lotes privados no Bairro Caramuru (b) em Patos de Minas. Fonte: AMORIM, 2015.
Com base na Figura 6 podemos perceber que os principais espaços livres geradores do traçado urbano ou inibidores da presença de traçado são os corpos d'água, juntamente com suas APP's estes se encontram em áreas de traçado urbano mais irregular (Figura 6a). O traçado urbano ortogonal regular muitas vezes contribui para a padronização espacial dos espaços livres, por exemplo: lotes de tamanho regular cuja legislação prevê a mesma porcentagem de área permeável e taxa de ocupação, contribuem para a formação de espaços livres privados no interior dos lotes homogêneos (Figura 6b).

As áreas destinadas a espaços públicos e equipamentos comunitários (espaços edificados) nos loteamentos aprovados correspondem a 15\% do tamanho da gleba, essa porcentagem não está relacionada com a densidade para qual o loteamento foi planejado, nem com as características ambientais, não garantindo a permeabilidade do solo nessas áreas, conforme lei municipal complementar de 2004 a qual permanece vigente.

Art. $5^{\circ} \mathrm{Em}$ qualquer loteamento deverá ser transferido ao domínio público, no mínimo, 35\% (trinta e cinco por cento) da área total do loteamento, destinados a logradouros públicos, vias de circulação, espaços livres de uso público, e áreas para equipamentos urbanos e comunitários.

Art. $6^{\circ}$ Da área correspondente a ser transferida para o domínio público, 15\% (quinze por cento), no mínimo, será destinada exclusivamente a equipamentos comunitários e áreas livres de uso público. (PATOS DE MINAS, lei complementar nº 216 de 04 ago. 2004) 
De acordo com Oseki e Pellegrino (2003), os espaços livres são lugares por excelência das intervenções capazes de conciliar questões ambientais e sociais, eles precisam ser pensados e concebidos buscando a socialização de espaços naturais e a (re)naturação dos espaços sociais. A padronização (dimensões e funções) dos espaços públicos também dificulta o processo de apropriação e criação de identidade nos bairros.

\section{Considerações}

Os espaços livres presentes na forma urbana patense foram incorporados ao longo do processo de urbanização. Eles se configuram a partir de porcentagens definidas pelo planejamento urbano, pelos agentes produtores do espaço (agentes municipais, estaduais, federais, o capital privado e os grupos sociais), por apropriações, características da paisagem, relações culturais, distribuição das reservas ambientais e APP's, além das pressões do mercado imobiliário. Para analisar a distribuição, hierarquia, configuração e relação sistêmica dos espaços livres presentes na forma urbana patense foi preciso estudar a cidade por diferentes ângulos: observando as relações ecológicas presentes na área de estudo, identificando a configuração espacial e as relações fundiárias desses espaços.

Durante a aplicação metodológica foram elaborados outros mapas temáticos além dos apresentados no presente artigo, dentre eles: a distribuição dos espaços ivres a partir dos tipos das funções que desempenham; distribuição das categorias de espaços livres na cidade; distribuição das praças implantadas e não implantadas e principais agentes produtores do espaço. Esses temas foram baseados em pesquisas sobre os espaços livres nas cidades brasileiras desenvolvidas pelo QUAPÁ-SEL. Porém, esses mapas pouco expressaram as especificidades da cidade, revelaram distribuições homogêneas. Foi necessário avaliar quais tipos de análises seriam mais pertinentes para evidenciar as características de Patos de Minas enquanto cidade média, ou seja, apesar da metodologia de mapeamento do SEL ser a mesma, as cidades podem demandar diferentes análises para caracterização de seus espaços livres.

A apreciação do Sistema de Espaços Livres de Patos de Minas e de sua importância na configuração da malha urbana evidenciou problemas como: o desconhecimento do conceito de SEL por parte do planejamento urbano; as atuais dificuldades de gestão e manutenção dos espaços livres; a disparidade de escala e de qualidade entre os espaços livres públicos e os privados; a ausência de programas que incentivem a arborização urbana, a conscientização ambiental e a valorização das características da paisagem local e a inexistência de um planejamento e gestão integrada dos espaços livres.

\section{Referências bibliográficas}

AMORIM, Nayara Cristina Rosa. O sistema de espaços livres na forma urbana de Patos de Minas. 2015. Dissertação (Mestrado em Arquitetura e Urbanismo). Universidade Federal de Uberlândia. Uberlândia, 2015.

ASSOCIAÇÃO DOS ENGENHEIROS DA SABESP - AESABESP. Poluição por carga difusa: o impacto da poluição difusa nos centros urbanos. Revista Saneas. n. 30, p. 14-25, ano IX, jul./ago./ set., 2008. Disponível em: <http://www.aesabesp.org.br/arquivos/saneas/saneas30.pdf>. Acesso em: nov. de 2017. 
BONZI, R. S. Andar sobre Água Preta: a aplicação da Infraestrutura verde em áreas densamente urbanizadas. São Paulo: SiBi-USP, 2015.

CAMPOS, A. C. M. A. (Org.); QUEIROGA, E. F. (Org.); GALENDER, F. (Org.); DEGREAS, H. N. (Org.); AKAMINE, R. (Org.); MACEDO, S. S. (Org.); CUSTÓDIO, V. (Org.). Quadro dos sistemas de espaços livres nas cidades brasileiras. 1. ed. São Paulo: FAUUSP, 2012. v. 1. p. 232-239.

GORSKI, M. C. B. Rios e cidades: ruptura e reconciliação. São Paulo: Editora Senac, 2010.

IBGE - Instituto Brasileiro de Geografia e Estatística. Disponível em: <http://www.cidades.ibge. gov.br/xtras/perfil.php?lang=\&codmun=314800\&search=minasgerais/patos-de-minas $>$. Acesso em: janeiro de 2016.

MACEDO, Silvio Sores; QUEIROGA, Eugenio Fernandes; GALANDER Fany Cutcher; CAMPOS, Ana Cecília de Arruda; CUSTÓDIO, Custódio; DEGREAS, Helena; GONÇALVES Fabio Mariz. Os sistemas de espaços livres na constituição da forma urbana contemporânea no Brasil: produção e apropriação (QUAPÁ-SEL II). Revista Paisagem e ambiente: Ensaios n 30, p. 137-172. São Paulo: 2012.

OSEKI, J.; PELLEGRINO, P. Sociedade e Ambiente, Capitulo 8. FAUUSP, São Paulo, 2003.

PATOS DE MINAS, Prefeitura Municipal. Mapas concedidos pela Secretaria de Planejamento Urbano. Patos de Minas, 2015.

PATOS DE MINAS, Prefeitura Municipal. Lei de Uso e Ocupação do Solo de Patos de Minas. Lei Complementar n 320 de 31 de dezembro de 2008. Art. 11, Capítulo IV, Seção II- Áreas Verdes. Disponível em: <http://www.patosdeminas.mg.gov.br/home/>. Acesso em: nov. de 2017.

PATOS DE MINAS, Prefeitura Municipal. Lei complementar n² 216 -. Dispõe sobre o Parcelamento do Solo Urbano no Território do Município de Patos de Minas e dá outras providências. De 04 de agosto de 2004.

PINHEIRO, Maitê Bueno. Plantas para infraestrutura verde e o papel da vegetação no tratamento das águas urbanas de São Paulo: identificação de critérios para seleção de espécies. Dissertação (Mestrado), FAUUSP. São Paulo, 2017.

QUEIROGA, Eugenio Fernandes, MACEDO Silvio Soares, CAMPOS Ana Cecília, GONÇALVES Fabio, GALENDER, Fany, DEGREAS, Helena, AKAMINE, Rogério, CUSTÓDIO, Vanderli. Sistemas de espaços livres: conceitos, conflitos e paisagens. São Paulo: FAUUSP, p. 11-20, 2011.

RIBEIRO, Maria Elisa Jubé. Infraestrutura verde: uma estratégia de conexão entre pessoas e lugares. Por um planejamento urbano ecológico para Goiânia. Tese (Doutorado em Arquitetura e Urbanismo). FAUUSP, São Paulo, 2010.

SCHELEE, M. B.; NUNES, M. J.; REGO, A. Q.; RHEINGANTZ, P. A.; DIAS, M. A.; TÂNGARI, V. R. Sistemas de Espaços Livres nas cidades brasileiras - um debate conceitual. Sistemas de Espaços Livres: o cotidiano, apropriações e ausências. Rio de Janeiro, 2009, p. 28- 49.

SOUZA, Conrado Blanco de \& MACEDO, Silvio Soares. APP's fluviais urbanas e sistemas de espaços livres: o papel da legislação ambiental na configuração do espaço urbano à beira d'água. $3^{\circ}$ Seminário Nacional sobre o Tratamento de Áreas de Preservação Permanente em Meio Urbano e Restrições Ambientais ao Parcelamento do Solo. Universidade Federal do Pará. Belém, 2014.

SPIRN, Anne W. The Granite Garden - urban nature and human design. Nova lorque: Basic Books, Inc., Publishers, 1984

TARDIN, Raquel. Ordenação sistêmica da paisagem. In: ENANPARQ - Encontro Nacional da Associação Nacional de Pesquisa e Pós-Graduação em Arquitetura e Urbanismo, $1^{\circ}$, Rio de Janeiro, 2010. 